\title{
Ilustração de espécimes de Violaceas presentes no campus da Uefs.
}

\author{
Lucas Carneiro dos Santos $^{1}$; Ivoneide de França Costa ${ }^{2}$; \\ 1. Bolsista PIBIC/CNPq, Graduando em Nome do Curso, Universidade Estadual de Feira de Santana, e-mail: \\ lucascarneirods@hotmail.combr \\ 2. Orientador, Departamento de nome, Universidade Estadual de Feira de Santana, e-mail: neidefc@uefs.br
}

PALAVRAS-CHAVE: Desenho, Ciência, Violaceaes.

\section{INTRODUÇÃO}

Ao longo do desenvolvimento da humanidade e o surgimento da oralidade o desenho também pode se desenvolver como uma linguagem própria, aperfeiçoando seu caráter descritivo e ao mesmo tempo interpretativo (CARNEIRO, 2011). Desde esse período, o desenho tem sido um dos mais eficazes meios de comunicação e expressão.

Através do Renascimento Cultural, na Europa do século XIV, a matemática e às ciências da natureza ganharam grande destaque, influenciando esteticamente artistas do período. Isso permitiu o desenvolvimento de novas técnicas de proporção e perspectiva, através das quais a pintura e a escultura renascentista pretendiam se aproximar ao máximo da realidade. Nesse período, surge a ciência moderna e junto com ela uma visão da arte do desenho como instrumento da ciência, a ilustração científica. A principal função desse poderoso instrumento está na capacidade de representação, visto que "o desenho é uma das formas de expressão humana que melhor permite a representação das coisas concretas e abstratas que compõem o mundo natural ou artificial em que vivemos" (GOMES, 1996, p. 13).

O cientista se utiliza do desenho para realizar experimentos, a fim de obter meios de investigação operativa (BELLUZZO, 1994), como também para confirmar os dados obtidos em experimentações. Ou seja, o desenho se apresenta ao cientista como elemento fundamental para o desenvolvimento e comprovação da ciência.

Nesse sentido, presente plano de trabalho teve por objetivo pesquisar e representar graficamente plantas através de técnicas de ilustração cientifica. Objeto escolhido para estudo foram plantas pertencentes à família Violacea. Embora não seja um grupo muito comum, as Violaceas apresentam distribuição cosmopolita, possuindo representantes em diversos ecossistemas. Segundo Souza \& Lorenzi (2012), o interesse econômico desse grupo de plantas concentra-se nas espécies ornamentais, com destaque para a Viola tricolor, também conhecida popularmente como amor perfeito; e espécies de violeta (Viola spp.). Já outras espécies são empregadas para fins medicinais, como é o exemplo da chamada ipecacuanha-branca (Pombalia spp.). Essa planta é utilizada no tratamento da tosse e é encontrada amplamente no campus da Universidade Estadual de Feira de Santana (UEFS).

Violacea também é um dos muitos grupos de plantas que atualmente estão sendo estudadas no projeto desenvolvido no âmbito da UEFS em conjunto com outras universidades públicas do estado da Bahia, intitulado Flora da Bahia, cujo objetivo é identificar e catalogar as plantas que ocorrem no estado da Bahia. Sendo assim, o trabalho veio a contribuir para o andamento desse projeto.

\section{MATERIAL E MÉTODOS OU METODOLOGIA (ou equivalente)}

Os materiais utilizados durante o desenvolvimento das atividades do plano de trabalho foram: lápis grafite, tinta aquarela, papel canson e máquina fotográfica, todos disponibilizados pelo projeto de pesquisa a que o presente plano se vincula. A identificação das espécies foi feita em conjunto com outros pesquisadores botânicos do 
herbário da UEFS que desenvolvem trabalhos sobre espécies de Violaceae na Bahia. As plantas foram representadas através da técnica de grafite

\section{RESULTADOS E/OU DISCUSSÃO (ou Análise e discussão dos resultados)}

Com o intuito de melhorar a compreensão e sua utilização na vida humana, as plantas tornaram-se fonte de investigação muito antes do surgimento da ciência. A partir da necessidade de conhecer e identificar as plantas, o desenho passou a ser utilizado na caracterização e descrição dos vegetais. Sociedades antigas, como os egípcios, utilizavam de gravuras para representar os vegetais usados em sua culinária e na medicina, por exemplo, como afirma Pereira:

\footnotetext{
Os desenhos botânicos são utilizados na descrição e identificação taxonômica de plantas. Eles são encontrados em estudos de anatomia vegetal, citologia, ecologia e morfologia. As ilustrações são uteis em publicações de divulgação cientifica, como jornais e revistas, livros e guias de campo, rótulos de fármacos e cosméticos (PEREIRA, 2008).
}

A ilustração científica é um tipo de representação que tem por objetivo traduzir e comunicar, através das imagens, observações e conhecimentos científicos; elucidando seus aspectos e dando-lhes maior visibilidade. Uma das principais características que a defini é a possibilidade de destacar, através do foco, detalhes que são de interesse do ilustrador.

Deve-se ressaltar que uma ilustração científica não é necessariamente uma cópia do que se vê. Segundo Pereira (2007), mesmo que o desenho se constitua como uma representação fiel, ele não deixa de ser uma interpretação do modo tanto de ver quanto de registrar graficamente.

A história da ilustração cientifica está intimamente associada ao desenvolvimento da própria ciência:

Esse novo gênero artístico nasceu vigoroso na renascença, facilitada pela realidade das espécies naturais provenientes do novo mundo. Em decorrência das viagens feitas, então, ampliam-se extraordinariamente os arquivos de criaturas e plantas, o que acabou incentivando, cada vez mais, o empenho dos enciclopedistas, dos colecionadores e da nobreza em geral em guardar essas coleções em gabinetes de curiosidades. (PEREIRA, 2008).

Existe uma grande variedade de meios e técnicas que podem ser utilizadas em uma ilustração científica biológica. A escolha depende, entre outras coisas, do tempo disponível e da finalidade da publicação. Dentre as técnicas mais utilizadas nas publicações científicas estão o grafite, tintas guache, nanquim, acrílica e computação gráfica (PEREIRA, 2007). Em todas elas, o olhar sobre o objeto é importante. Observar a diversidade de formas e cores que compõem a natureza requer tempo e sensibilidade.

Uma convenção bem firmada é o posicionamento do foco luminoso. $\mathrm{Na}$ ilustração cientifica a luz deve-se localizar, sempre, do lado esquerdo e acima em relação ao objeto que vai ser desenhado:

$\mathrm{Na}$ ilustração é usual que a fonte de luz primaria esteja num ângulo de 45 graus em relação ao plano que o objeto se apoia. Para auxiliar na percepção da tridimensionalidade da forma, deve-se localizar uma fonte de luz secundaria, ou luz refletida, à direita, logo à baixo do plano de apoio. (PEREIRA, 2007). 
Embora não seja um grupo muito comum, as Violaceas apresentam distribuição cosmopolita, possuindo representantes em diversos ecossistemas. Grande parte das plantas pertencentes a essa família são ervas de regiões temperadas.

Atualmente foram catalogadas 800 espécies pertencentes à família Violaceae em todo mundo, organizadas filogeneticamente em 21 gêneros. No Brasil ocorrem 14 desses gêneros com cerca de 74 espécies, a maioria pertencente ao gênero Pombalia e Rinorea. Na Bahia, as Violaceaes incluem 9 gêneros e 23 espécies. O maior deles é o gênero Pombalia que possui 10 espécies, encontradas principalmente em campus rupestres, cerrados e caatingas. Dentro do gênero Pombalia, selecionamos como objeto de estudo três espécies que possuem grande ocorrência no campus da UEFS: Pombalia arenaria, Pombalia calceolaria e Pombalia glauca.

As espécies Pombalia calceolaria e Pombalia arenaria são bastante próximas morfologicamente, diferindo na forma em que o tricoma se apresenta: na primeira o tricoma é do tipo simples e a segunda possui tricomas de duas formas, simples e estrelado. Já a Pombalia glauca difere bastante das duas por possuir folhas opostas, membrana cartilaginosa na base da folha e não apresentar tricoma.

Essas características morfológicas são utilizadas na classificação e organização dessas espécies. Assim, toda publicação botânica destinada à descrição desses espécimes devem apresentar ilustrações desses caracteres. Isso torna evidente o importante papel do desenho em relação ao conhecimento científico.

Realizamos a descrição das três espécies da forma como é exigido pelos veículos de publicação. Os caracteres foram denominados através de termos científicos botânicos.

\section{Ilustrações produzidas:}
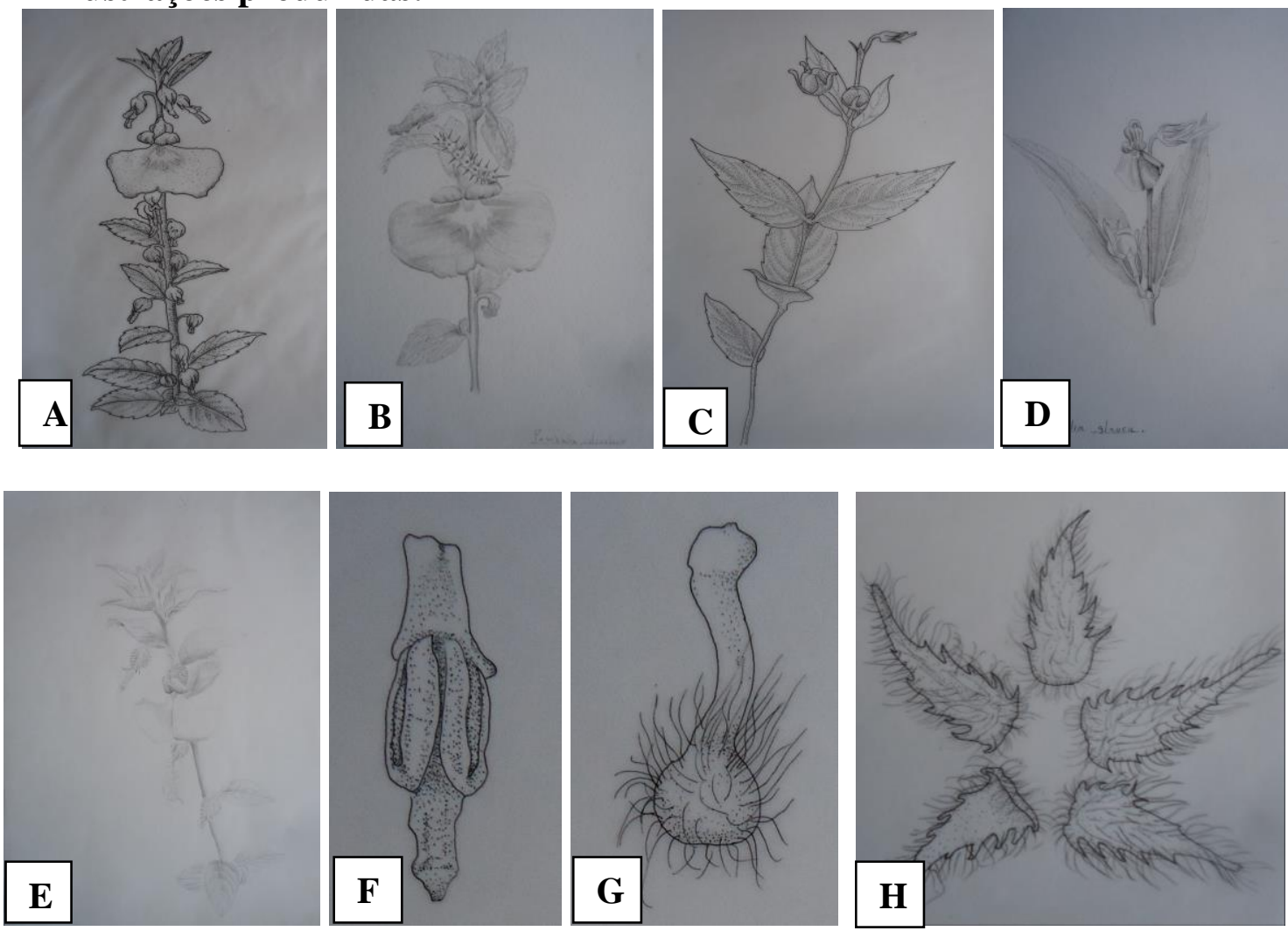

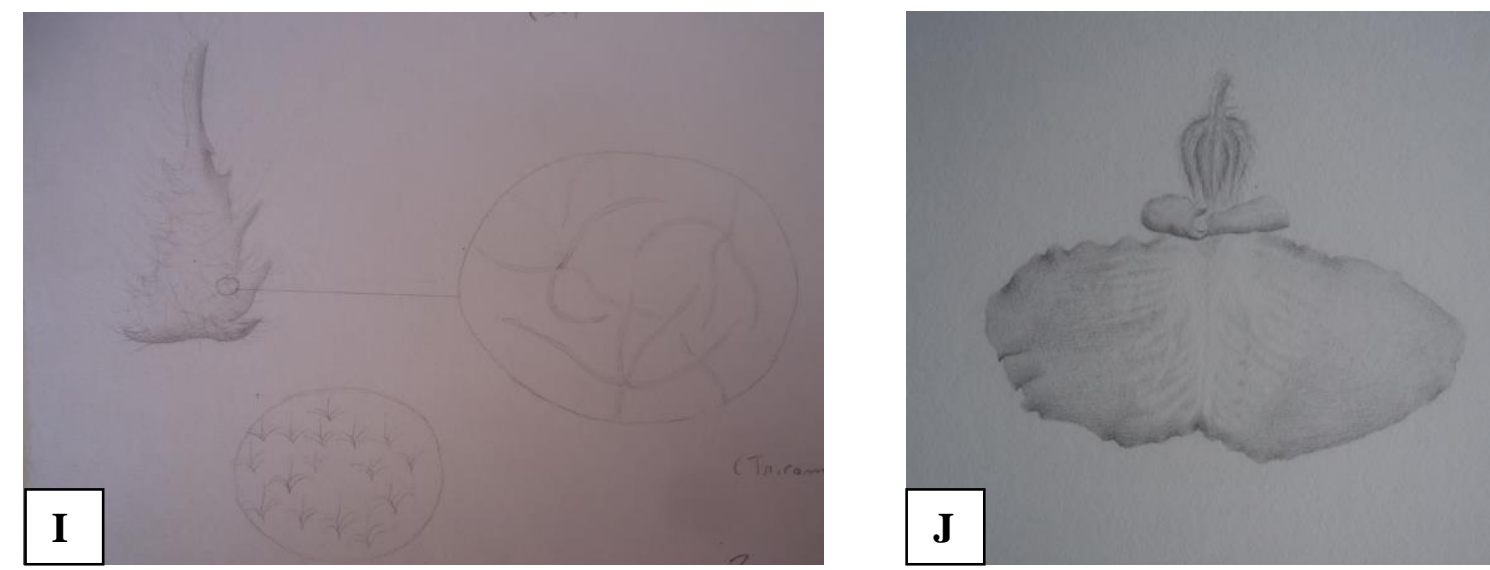

Figura 1: A e B - Pombalia arenaria (Hábito); C e D - Pombalia glauca. (Hábito); E - Pombalia calceolaria. (Hábito); Estruturas reprodutivas: F - Estame; G Ovário; H - sépalas; I - Tricoma estrelado; J - Flor. A, C, F, G e H - Representação em nanquim; B, D, E, I e J - Representação em grafite.

\section{CONSIDERAÇÕES FINAIS (ou Conclusão)}

Embora seja um grupo monofiletico (todas as espécies incluídas na família possuem o mesmo ancestral evolutivo) as relações dentro do grupo Violaceae são pouco compreendidas (Judd et al, 2009). Os trabalhos e literaturas existentes sobre a família em questão ainda são um pouco escassos, dessa forma espera-se que o presente trabalho e os desenhos produzidos venham contribuir para futuros trabalhos sobre as espécies de gênero Pombalia, auxiliando na identificação e no estudo das relações estre as espécies.

\section{REFERÊNCIAS}

PEREIRA, R. M. A. Cadernos de Ilustração Científica 1: ABCDesenho. PROEX UFMG- Pró Reitoria de extensão, Belo Horizonte, 2007.

PEREIRA, Rosa Maria Alves, Cadernos de Ilustração Científica 2, Ilustração Botânica, PROEX UFMG- Pró Reitoria de extensão, Belo Horizonte, 2008.

Claudio Luiz Mangini Juliana Cavalaro. Ilustrador. IFPR - INSTITUTO FEDERAL DO PARANÁ. 2012

CARNEIRO, Diana. Ilustração Botânica: Princípios e Métodos. Curitiba, PR: Editora UFPR, 2011.

GOMES, Luis Vidal Negreiros. Desenhismo. 2 ed. Santa Maria: UFSM, 1996

Paula-Souza, J. Levantamento das espécies de Hybantus Jacq. (Violaceae) do Brasil. Dissertação de Mestrado - Intituto de Biociências da Universidade de São Paulo Departamento de Botânica, 2009. 